\title{
Connexin 43 Modulates Osteogenic Differentiation of Bone Marrow Stromal Cells Through GSK-3beta/Beta-Catenin Signaling Pathways
}

\author{
Fei-xiang Lin ${ }^{a, b}$ Gui-zhou Zheng ${ }^{a}$ Bo Chang ${ }^{a, c}$ Rong-chun Chen ${ }^{b}$ \\ Qi-hao Zhang ${ }^{a, c}$ Peng Xie ${ }^{a}$ Da Xie ${ }^{a, c}$ Guo-yong Yuc Qin-xiao Hu ${ }^{a, c}$ \\ De-zhong Liuc Shi-xin Du ${ }^{a}$ Xue-dong Lia
}

aDepartment of Orthopedics, The Third Affiliated Hospital (The Affiliated Luohu Hospital) of Shenzhen University, Shenzhen, bDepartment of Spine Surgery, The Affiliated Ganzhou Hospital of Nanchang University (Ganzhou People's Hospital), Ganzhou, cDepartment of Neurological Surgery, The First Affiliated Hospital of Shantou University Medical College, Shantou, P. R. China

\section{Key Words}

Connexin 43 - Osteogenic differentiation - Bone marrow stromal cells - GSK-3beta - Betacatenin

\begin{abstract}
Background/Aims: Bone marrow stromal cells (BMSCs) are multipotent precursors that give rise to osteoblasts, and contribute directly to bone formation. Connexin 43 (Cx43) is the most ubiquitous gap junction protein expressed in bone cell types, and plays crucial roles in regulating intercellular signal transmission for bone development, differentiation and pathology. However, the precise role and mechanism of Cx43 in BMSCs are less known. Here, we investigate the function of $\mathrm{Cx} 43$ in osteogenic differentiation of BMSCs in vitro. Methods: BMSCs were isolated by whole bone marrow adherent culture. Knock down of Cx43 was performed by using lentiviral transduction of $\mathrm{Cx} 43$ shRNA. BMSCs were induced to differentiate by culturing in a-MEM, 10\% FBS, $50 \mu \mathrm{M}$ ascorbic acid, $10 \mathrm{mM}$ beta-glycerophosphate, and $100 \mathrm{nM}$ dexamethasone. Alkaline phosphatase (ALP) activity and alizarin red S staining were used to evaluate osteogenic differentiation in calcium nodules. Target mRNAs and proteins were analyzed by using real-time quantitative PCR ( $q P C R$ ) and western blotting. Results: $C x 43$ expression markedly increased during osteogenic differentiation. Osteogenic differentiation was suppressed following lentiviral-mediated knockdown of Cx43 expression, as judged by decreased levels of Runt-related transcription factor 2 (Runx2), bone sialoprotein (BSP), osteocalcin (Bglap), Osterix (Osx), alkaline phosphatase (ALP) activity and the number of calcium nodules in response to osteogenic differentiation stimuli. Knock down of Cx43 reduced

F.-x. Lin, G.-z. Zheng and B. Chang contributed equally to this work.

Shi-Xin Du

and Xue-Dong Li

Department of Orthopedics, The Third Affiliated Hospital (The Affiliated Luohu

Hospital) of Shenzhen University, Shenzhen 518000, Guangdong (China)

Tel. +86-0755-25650005 E-Mail dsx1232013@sina.com, xdl622@sina.com
\end{abstract}

KARGER 
the level of phosphorylation of GSK-3beta at Ser9 (p-GSK-3beta), resulting in decreased beta-catenin expression and activation. Furthermore, treatment of Cx43-knockdown cells with lithium chloride (LiCl), a GSK-3beta inhibitor, reduced osteogenic differentiation and decreased GSK-3beta levels, as well as partially rescued levels of both total and activated beta-catenin. Conclusion: These findings indicate that $\mathrm{C} \times 43$ positively modulates osteogenic differentiation of BMSCs by up-regulating GSK-3beta/beta-catenin signaling pathways, suggesting a potential role for $\mathrm{C} \times 43$ in determining bone mass and bone mineral density by modulating osteogenesis.

(C) 2018 The Author(s)

Published by S. Karger AG, Basel

\section{Introduction}

BMSCs are multipotent adult stem cells that have self-renewing, proliferative potential and the ability to differentiate into a variety of cell types, including osteoblasts, adipocytes, chondrocytes, neurons and myoblasts $[1,2]$. Differentiation of BMSCs into adipocytes and osteoblasts is regulated in an inverse manner [3, 4], and plays a key role in the fate of BMSCs and bone mass. Under normal conditions, the balance between adipogenic and osteogenic differentiation of BMSCs is weighted toward osteogenic differentiation to maintain normal bone formation [5-7]. However, the balance of BMSC differentiation can be disrupted under pathological circumstances $[3,7]$. For example, BMSCs from osteoporotic women have a low growth rate and exhibit enhanced adipocyte differentiation that proceeds at the expense of osteogenesis, leading to low bone mass and a high marrow fat mass [8-10]. Many factors have been identified as key determinants in the process of osteogenic differentiation by BMSCs, and many studies have demonstrated that a change in the expression and/or activity of these factors is associated with bone formation or bone loss [11-13]. Therefore, understanding the cellular and molecular factors that influence BMSC fate may provide us with potential therapeutic targets for several diseases associated with bone loss and high marrow adiposity.

The cell surface contains gap junctions that consist of connexins, in particular $\mathrm{Cx} 43$, which mediate cellular communication and permit the passage of small molecules and ions between cells $[14,15]$. Cx43, encoded by the Gja1 gene, is the most ubiquitous gap junction protein expressed in bone cell types, including chondrocytes, osteoblasts, osteocytes, osteoclasts, and BMSCs $[14,16]$. Cx43 plays important roles in regulating signal transmission among different bone cell types and thereby regulates development, differentiation, modeling and remodeling, as well as pathologies of bone [16-19]. Cx43 is required for survival [20], proliferation [21] and differentiation [22-30] of different types of osteoblasts, for instance, MC3T3-E1 [28], UMR 106 [29], or mouse osteoblasts, and in 3D cultures [30], overexpression of $\mathrm{Cx} 43$ in BMSCs enhances both the magnitude and spatial distribution of gap junction intercellular communication and the expression of osteogenic markers 32[31]. However, the role of $\mathrm{Cx} 43$ in BMSCs remains obscure, and the mechanism by which Cx43 enhances osteogenic differentiation has not yet been established.

Loiselle et al. reported that deletion of $\mathrm{Cx} 43$ in osteoblasts/osteocytes results in delay of bone formation and bone remodeling, and impairs mechanical properties33 [32], and the mechanisms by which healing is impaired are related to altered activity of GSK-3beta, and therefore beta-catenin expression, during fracture healing 34[31]. Several signaling pathways have been shown to participate in the regulation of osteogenesis [13]. The Wnt/beta-catenin signaling pathway is an essential pathway for BMSC commitment to osteogenic differentiation [33-35]. Without Wnt ligands, cytoplasmic beta-catenin undergoes phosphorylation and degradation by a destruction complex composed of GSK-3beta, adenomatous polyposis coli and axin [36]. In contrast, when Wnt ligands bind to their cell surface receptors, inactivation of GSK-3beta occurs, leading to beta-catenin stabilization and translocation to the nucleus, where it binds to the T-cell factor/lymphoid-enhancer factor and activates transcription of Wnt target genes, such as axin 2 and cyclin D1 [36, 37]. Inhibitors of GSK-3beta can cause stabilization and accumulation of cellular beta-catenin to initiate the expression of target 
Lin et al.: Cx43 Modulates Osteogenic Differentiation

genes, resulting in an increase in osteogenic differentiation of BMSCs [35, 37]. These give us clues about mechanisms by which $\mathrm{Cx} 43$ regulates osteogenic differentiation of BMSCs. Therefore, we characterized the role of $\mathrm{Cx} 43$ in osteogenic differentiation of BMSCs and tested the hypothesis that Cx43 modulates osteogenic differentiation of BMSCs through GSK3beta/beta-catenin signaling pathways.

\section{Materials and Methods}

Animals

All experiments using laboratory animals were conducted according to the guidelines of the institutional animal care committee and were approved by the Animal Use Committee of Shantou University Medical College. Sprague-Dawley rats were housed in the Experimental Animal Center of Shantou University Medical College, and were maintained at an indoor temperature of $22^{\circ} \mathrm{C}$, relative humidity of $18 \%$ to $22 \%$, and a 12-h light/dark cycle. Ad libitum access to standard rodent chow and water was allowed during the entire study.

\section{Isolation and culture of BMSCS}

Primary BMSCs were isolated from four or more randomly selected 6-week-old Sprague-Dawley rats, weighing approximately 100 to150 g, according to an established protocol described previously [38, 39]. After SD rats were euthanized, tibias and femurs were immediately removed, and attached muscle and tissue were removed using a scalpel under sterile conditions. Then the metaphysis of the bone was cut off, and bone marrow was repeatedly flushed into a $10 \mathrm{~cm}$ Petri dish by using a $5 \mathrm{ml}$ injection syringe with basal medium (alpha-MEM (Gibco, \#C12571500BT, abbreviated as BAM) supplemented with 10\% (v/v) fetal bovine serum (Gibco, \#12664025), and 1\% (v/v) penicillin-streptomycin solution (Hyclone, \# SV30010)). The cell suspension was plated equally into three $10 \mathrm{~cm}$ petri dishes and cultured in a humidified incubator at $37^{\circ} \mathrm{C}$, with $5 \% \mathrm{CO}_{2}$ and $95 \%$ air. BAM was refreshed 2 days later to remove non-adherent cells, and changed 3 or 4 times a week. After 7 to 9 days in culture, when the adherent cells reached $80-90 \%$ confluence, cells were initially passaged at a split ratio of 1:2 using 0.25\% trypsin (AMRESCO, \#0458). Cells after passage 1 were subcultured at a split ratio of 1:3 about every 3 days, or plated for subsequent experiments.

\section{Lentivirus infection}

Lentiviral vectors (H1/GFP\&Puro), expressing GFP and either a Cx43 short-hairpin RNA (shCx43) or a scrambled shRNA, were both generated by GenePharma (Suzhou, China). The sequence targeting the coding region of rat Cx43 mRNA was: 5'- GCAATTACAACAAGCAAGCTA -3' [40], and the scrambled sequence used as the negative control (NC) was: 5'-ACTACCGTTGTTATAGGTG-3'. The virus titer used for infection was $10^{9} \mathrm{pfu} / \mathrm{ml}$. Passage 1 BMSCs were inoculated into 6-well plates at a density of $8 \times 10^{4}$ to $10^{5}$ cells per well and allowed to attach overnight. Then cells were refed with BAM containing $10 \mu \mathrm{g} / \mathrm{ml}$ polybrene (Sigma, \#H9268) and incubated for one hour prior to addition of lentivirus at a multiplicity of infection between 50 to 300 . The incubation medium was replaced with fresh BAM at 24 hours after infection, and live BMSCs were obtained following selection in growth medium, containing $2 \mu \mathrm{g} / \mathrm{mL}$ puromycin (Sigma, \#P8833), for two days. GFP fluorescence was detectable using an inverted fluorescence microscope (Nikon, \#ECLIPSE TE2000-S).

\section{Osteogenic differentiation}

Passage 3 BMSCs were plated at a density of 5000-10000 cells $/ \mathrm{cm}^{2}$ and incubated in osteogenic induction medium (OIM) consisting of a-MEM, 10\% FBS, $50 \mu \mathrm{M}$ ascorbic acid (Sigma, \#A4544), $10 \mathrm{mM}$ betaglycerophosphate (Sigma, \#G9422), 100 nM dexamethasone (Sigma, \#D1756), and 1\% (v/v) penicillinstreptomycin solution. Cultures were gently refed every 2-3 days with OIM until cells were harvested for experiments. Since the process of osteogenic differentiation of BMSCs is progressive, we assayed biochemical parameters at early and later phases corresponding to 7 days and 14 days of osteogenic differentiation, respectively. 


\section{Cellular Physiology Cell Physiol Biochem 2018;47:161-175 \begin{tabular}{l|l} 
and Biochemistry Published 10.1159/000489763 & $\begin{array}{l}\text { C) } 2018 \text { The Author(s). Published by S. Karger AG, Basel } \\
\text { www.karger.com/cpb }\end{array}$
\end{tabular}}

Lin et al.: Cx43 Modulates Osteogenic Differentiation

Quantitation of ALP activity

ALP activity is elevated early following induction of differentiation, but decreases at later stages, so we choose the 9-day time point to determine ALP activity. Activity was measured using an ALP measurement kit (Beyotime, \# P0321). Briefly, cells were lysed with 1\% Triton X-100 and centrifuged at $4^{\circ} \mathrm{C}, 1000 \mathrm{rpm}$. Supernatants were transferred to a clean tube, then subjected to the ALP assay according to the manufacturer's protocol. Absorbance was measured at $405 \mathrm{~nm}$ by a 96 -well plate microplate reader (Thermo Scientific).

\section{Alizarin red $S$ staining and quantification of calcium nodules}

Cells were differentiated by continuous incubation in OIM for 14 days in 12-well plates, then gently washed twice with phosphate-buffered saline (PBS), fixed with absolute ethanol for 15 minutes, rinsed once with double-distilled water, and then incubated in $0.1 \%$ alizarin red S solution (Panera, \#AAPR122-A1) for 30 minutes. After washing cells twice with double-distilled water and drying completely, the stained calcium nodules were photographed under a light microscope. To quantify the calcium nodules, dye was eluted in cetyl pyridinium chloride (Sigma, \# 588393) in $10 \mathrm{mM}$ sodium phosphate for $30 \mathrm{~min}$, and the absorbance was then measured at $540 \mathrm{~nm}$ with a 96-well plate microplate reader (Thermo Scientific). The entire process was conducted at room temperature.

\section{RNA extraction and $q P C R$}

At 7 or 14 days of differentiation with OIM, total RNA was extracted with an RNA extraction kit (TaKaRa, \#9767) according to the manufacturer's instructions, and total RNA concentration was determined with a SmartSpec Plus spectrophotometer (BIO-RAD). First-strand cDNA was synthesized using a PrimeScript ${ }^{\mathrm{TM}}$ RT Master Mix (TaKaRa, \#RR036A) from $1000 \mathrm{ng}$ total RNA in a $20 \mu \mathrm{l}$ total reaction volume. qPCR was performed with SYBR® Premix Ex TaqTM (TaKaRa, \#RR420A) using a CFX96 qPCR Detection System (BIO-RAD Laboratories) in a total reaction volume of $25 \mu \mathrm{L}$. Primer sequences are listed in Table 1. Glyceraldehyde-3-phosphate dehydrogenase (GAPDH) was used as the internal control, and relative gene expression levels were calculated by means of the $2-\Delta \Delta \mathrm{Ct}$ method. Each experiment was performed at least three times independently.

\section{Protein preparation and western blotting analyses}

After differentiation with OIM for 7 or 14 days, cells were washed with PBS and total protein was extracted. In brief, cells were prepared by lysing with radioimmunoprecipitation assay (RIPA) lysis buffer (Beyotime, \#P0013B) containing 1\% (v/v) protease inhibitor cocktail (Biotool, \#B14001) and 1\% (v/v) phosphatase inhibitor cocktail (Biotool, \#B14001). After centrifugation for 15 minutes at $4^{\circ} \mathrm{C}, 15000 \mathrm{rpm}$, protein concentrations of supernatants were determined using the Bradford method (Bio-Rad Laboratories). Approximately $50 \mu \mathrm{g}$ of protein per lane was separated by $8 \%$ or $10 \%$ SDS-PAGE, then transferred onto polyvinylidene fluoride membranes (Millipore, \#IPVH00010). After blocking in 5\% nonfat milk for 1 hour at room temperature, membranes were incubated with rabbit anti-Cx43 (1:1000, Cell Signaling Technology, \#3512), rabbit anti-GSK-3beta (1:1000, Cell Signaling Technology, \#9315), rabbit anti-phospho-GSK-3beta (1:1000, Cell Signaling Technology, \#9322), rabbit anti-beta-catenin (1:1000, Cell Signaling Technology, \#9581), rabbit anti-active betacatenin $(1: 1000$, Cell Signaling Technology, \#4270), or rabbit anti-GAPDH $\quad(1: 1000$, Panera, \#SF-PA005) primary antibodies overnight at $4^{\circ} \mathrm{C}$. The following day, membranes were washed three times in TBST (10 min each time), and incubated with horseradish peroxidase (HRP)conjugated goat anti-rabbit IgG (Jackson ImmunoResearch, \#111-035-003) antibodies for $1 \mathrm{~h}$ at room temperature. Then

Table 1. Primer sequence of qPCR

\begin{tabular}{lcc}
\hline Gene & Forward primer sequence & Reverse primer sequence \\
\hline Cx43 & TGCTTGGGATAGCTGGGCGGA & TGGGGGCAGAGAGAGAAAGCCC \\
& GGGACCGTCCACTGTCACTTT & \\
& AATA & CAAGTGGCCAGGTTCAACGA \\
BSP & GCTATGAAGGCTACGAGGGTC & \\
& AGGATTAT & \\
Bglap & AGGTGGTGTATAGGATAGACTCCG & GCTGTGCCGTCCATACTTT \\
Osx & GGAGGCACAAAGAAGCCATA & GGGAAAGGGTGGGTAGTCAT \\
Axin 2 & GACCGACGATTCCATGTCC & CCAGCTCCAGTTTCAGCTTC \\
Cyclin D1 & GCTGGCGTTTGGAAGTAG & CCTCAGTTTGGATGGCTC \\
GAPDH & TCCTGCACCACCAACTGCTTAG & AGTGGCAGTGATGGCATGGACT \\
\hline
\end{tabular}


membranes were washed three times in TBST (10 min each time), and protein bands were visualized using an enhanced chemiluminescence reagent (Thermo Scientific), imaged with Bio-Rad ChemiDoc-XRS+, and analyzed using Image Lab software (Bio-Rad). Protein values were normalized to GAPDH.

\section{Statistical analysis}

Each assay was performed more than three times independently. All values are expressed as the fold change over the control, and presented as means \pm standard deviation (SD). Statistical analysis was calculated using either two-way or one-way analysis of variance, and for experiments with three groups SPSS 19.0 software (SPSS Inc., Chicago, IL) was used. Differences were regarded as significant when $P<0.05$.

\section{Results}

\section{CX43 expression is upregulated during osteogenic differentiation}

Exposure of BMSCs to BAM or OIM for 7 and 14 days resulted in cells increasingly undergoing osteogenic differentiation with time, as revealed by alizarin red S staining (Fig. $1 \mathrm{~A}$ and $\mathrm{B})$. We analyzed the changes of the Cx43 mRNA and protein in BMSCs by qPCR and western blotting. Results indicated that Cx43 mRNA increased upon differentiation, as compared to undifferentiated cells, at both 7 and 14 days (Fig. 1C and D), as well as the level of $\mathrm{Cx} 43$ protein (Fig. 1E-H). These data suggest that up-regulation of $\mathrm{Cx} 43$ occurs upon differentiation, and that $\mathrm{Cx} 43$ may be involved in osteogenic differentiation of BMSCs.

\section{Knock down of CX43 attenuates osteogenic differentiation of BMSCs}

To further confirm the role of Cx43 in BMSC osteogenic differentiation, we established Cx43 knockdown BMSCs by infection with lentiviruses expressing shCx43. Viral efficacy

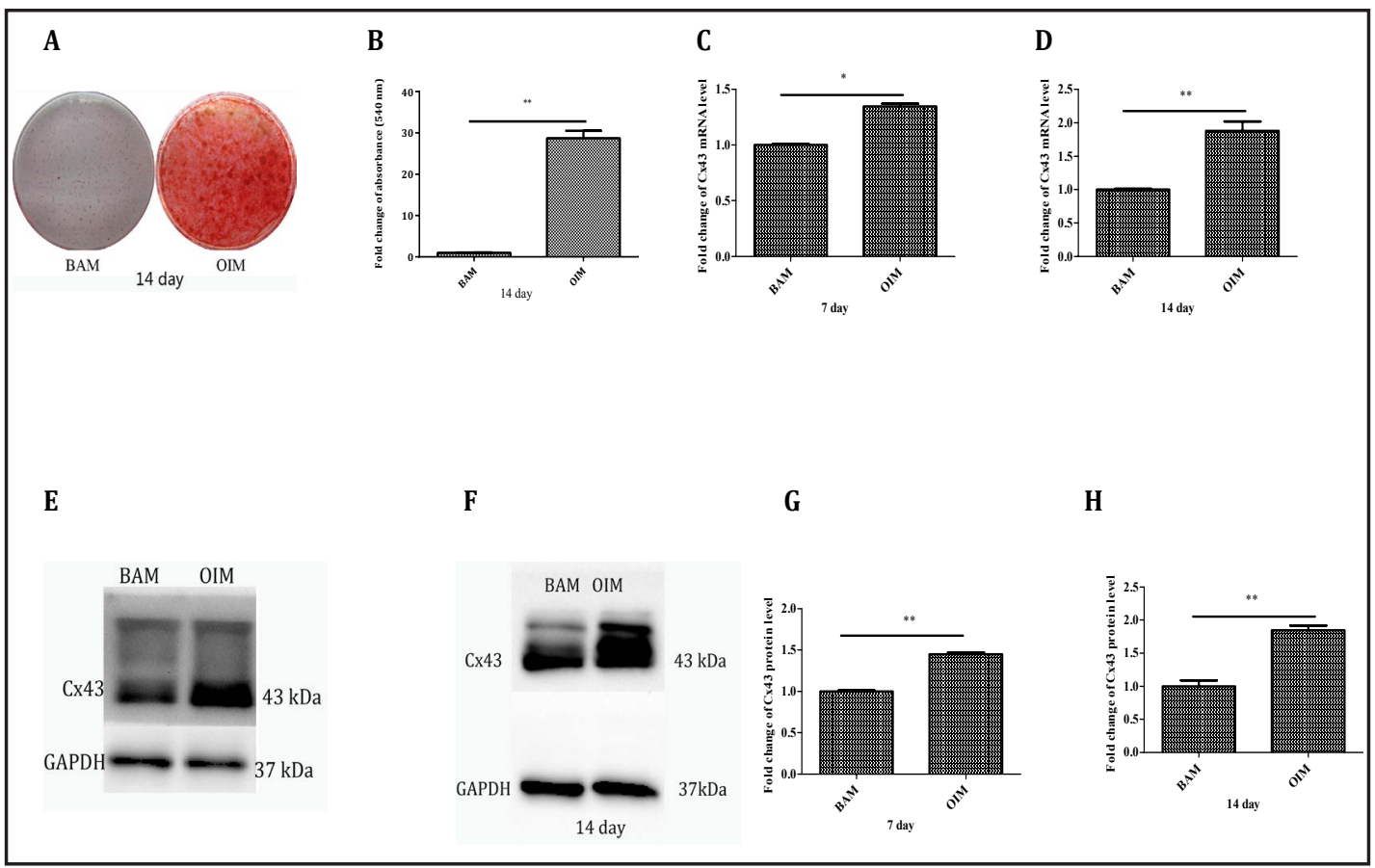

Fig. 1. Upregulation of $\mathrm{Cx} 43$ expression during osteogenic differentiation. (A), Calcium nodules were stained with alizarin red S, then photographed. (B), alizarin red staining was quantified. (C and D), Expression of Cx43 mRNA was measured by qPCR at 7 or 14 days after initiation of osteogenic differentiation. (E-H), Western blot analysis of $\mathrm{Cx} 43$ at 7 or 14 days following induction of osteogenic differentiation. Fold change in $\mathrm{Cx} 43$ protein expression following normalization to the values of BAM-cultured cells. Data are expressed as the mean $\pm S D$ of the fold change from three separate experiments $\left({ }^{*} p<0.05,{ }^{* *} p<0.01\right)$. 


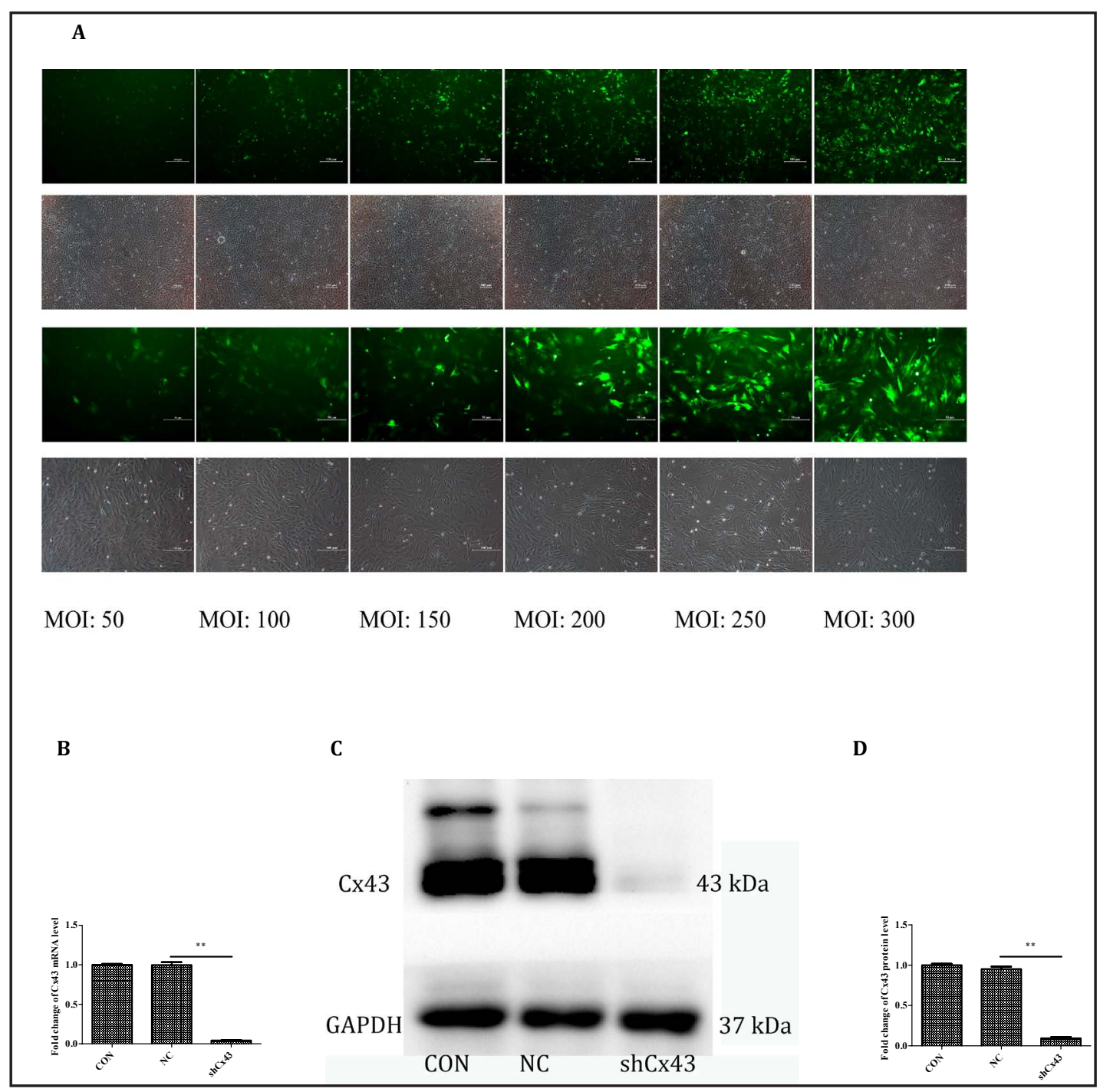

Fig. 2. Knockdown of Cx43 in BMSCs with lentivirus expressing Cx43 shRNA. (A), Bright field and GFP expression following virus infection at an MOI of 50, 100, 150, 200, 250 and 300 in passage 1 BMSC cells. Bar indicates $100 \mu \mathrm{m}$. (B and C), qPCR and western blotting analysis of Cx43 mRNA and protein levels in shCx43 BMSCs after lentivirus transduction at 300 MOI. Data are expressed as the mean \pm SD of the fold change following normalization to CON. Values represent analysis from three separate experiments $\left({ }^{* *} \mathrm{p}<0.01\right)$.

was tested using MOIs of 50,100, 150, 200, 250 and 300 to infect passage 1 BMSC cells. The virus had no effect on cell viability and approximately $90 \%$ of BMSCs were GFP-positive at 72 hours after lentivirus transduction at 300 MOI (Fig. 2A). Therefore, for knockdown studies, lentivirus transduction was carried out at $300 \mathrm{MOI}$, and stably transduced cells were selected by culture in puromycin-containing medium for 2 days, followed by continuous culture in BAM for 14 days. The mRNA expression was lower in shCx43 cells than that in both uninfected cells (as control: $\mathrm{CON}$ ) and NC cells (Fig. 2B). In accordance with the mRNA level, western blotting showed that the expression of CX43 protein was almost completely abrogated by lentivirus transduction (Fig. 2C and D).

To evaluate the ability of representative CON, NC and shCx43 BMSCs to undergo osteogenic differentiation, cells were cultured in BAM or OIM for the indicated times. After a 9-day differentiation period, Cx43-silenced cells displayed an approximately $50 \%$ decrease in ALP activity, as assessed by enzymatic measurement (Fig. 3A). We measured mineralization using alizarin red S staining following induction of differentiation for 14 


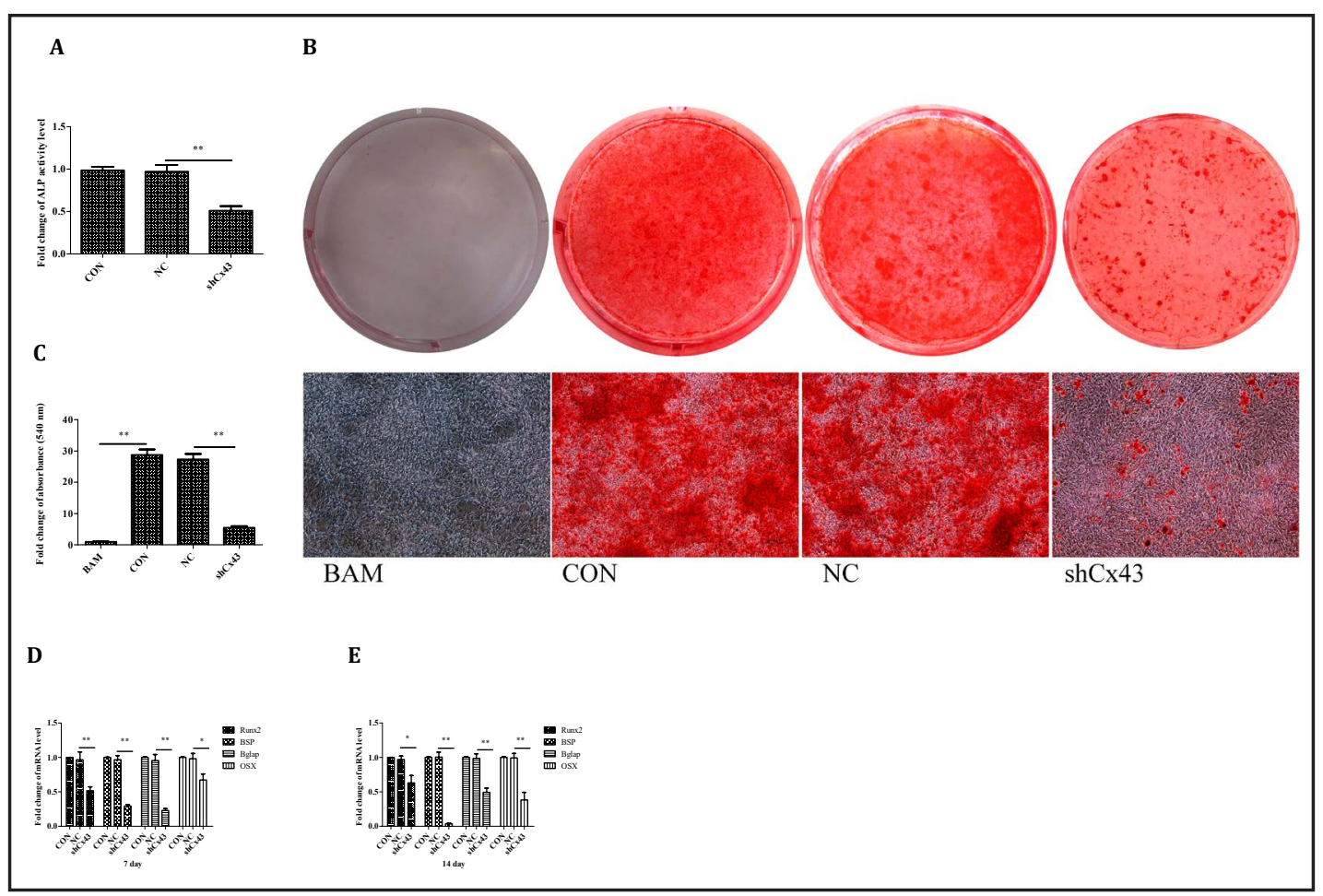

Fig. 3. Knockdown of $\mathrm{Cx} 43$ attenuates osteogenic differentiation of BMSCs. (A), ALP activity of BMSCs was observed in BMSCs at 9 days following differentiation. (B), alizarin red S staining was performed 14 days after induction, then photographed under bright field. Bar indicates $100 \mu \mathrm{m}$. (C), alizarin red S staining was quantified. (D and E), Expression of Runx2, BSP, Bglap and OSX was measured by real-time RT-PCR after 7 and 14 days of induction, respectively. Data are expressed as the mean fold change \pm SD of the values in CON. Values represent analysis from three separate experiments $\left({ }^{*} \mathrm{p}<0.05,{ }^{* *} \mathrm{p}<0.01\right)$.

days. Knockdown of $\mathrm{Cx} 43$ prior to osteogenic differentiation of BMSCs resulted in a $>80 \%$ decrease in mineralization (Fig. 3B and C) compared with CON and NC.

To investigate the molecular mechanism induced by Cx43 knockdown, the mRNA levels of marker genes for osteogenesis, specifically, Runx2, bone sialoprotein (BSP), Bglap, and OSX, were examined after 7 or 14 days of exposure to BAM or OIM. Consistent with the reduction of ALP activity and mineralization observed in shCx43 BMSCs, when compared with CON and NC cells, the mRNA levels of the osteogenesis marker genes in shCx43 BMSC were decreased by approximately 20\%-90\%, regardless of whether cells were induced to differentiate for 7 or 14 days (Fig. 3D and E). Taken together, these results suggest that ablation of $\mathrm{Cx} 43$ suppresses osteogenic commitment, as judged by inhibition of osteogenesis marker gene expression.

The GSK-3beta/beta-catenin pathway is involved in suppression of Cx43-mediated osteogenic differentiation of BMSCs

To investigate whether the GSK-3beta/beta-catenin pathway is affected by Cx43 during osteogenic differentiation of BMSCs, we examined alterations in this pathway in cells cultured with OIM for 7 and 14 days. Western blot analysis showed that the levels of p-GSK3 beta (inactive form phosphorylated at Ser9) were decreased by more than $40 \%$ during the early period ( 7 days) and by almost $40 \%$ during the later period ( 14 days) in shCx43 BMSCs following osteogenic differentiation, compared with levels in CON and NC cells (Fig. 4AD). Moreover, in response to $\mathrm{Cx} 43$ knockdown, total beta-catenin progressively decreased from the early period (nearly 15\%) to the later period (almost 80\%) following induction of osteogenic differentiation (Fig. 4A, B, E and F). Correspondingly, the activation of beta-

\section{KARGER}




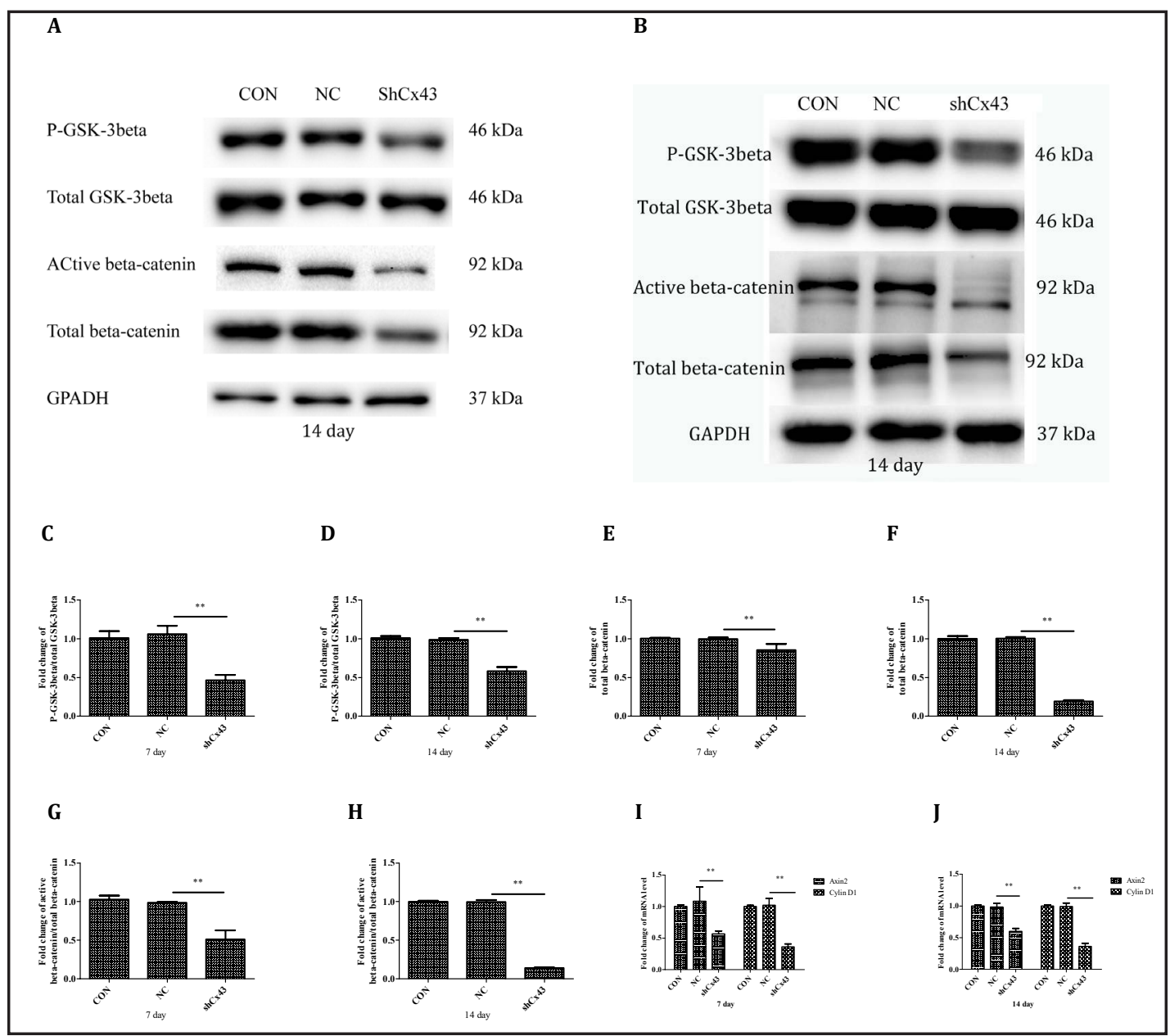

Fig. 4. GSK-3 $\beta / \beta$-catenin pathway is involved in suppression of osteogenic differentiation of BMSCs caused by $\mathrm{Cx} 43$. ( $\mathrm{A}$ and $\mathrm{B}$ ) Total protein was isolated after 7 and 14 days after start of induction, and the expression of phospho-GSK-3 $\beta$, total GSK-3 $\beta$, active $\beta$-catenin, and total $\beta$-catenin was analyzed by western blotting. The p-GSK-3beta/total GSK-3 beta ratio ( $\mathrm{C}$ and $\mathrm{D}$ ), total beta-catenin ( $\mathrm{E}$ and F) and active beta-catenin/total beta-catenin ratio ( $\mathrm{G}$ and $\mathrm{H}$ ) were quantified. (I and J), GSK-3 $\beta / \beta$-catenin pathway target gene mRNAs for axin 2 and cyclin D1 were measured by real-time RT-PCR after 7 and 14 days of induction. Data are expressed as fold change of the mean \pm SD following normalization to CON. Values represent analysis from three separate experiments $\left({ }^{*} \mathrm{p}<0.05,{ }^{* *} \mathrm{p}<0.01\right)$.

catenin was inhibited, being about $50 \%$ at 7 days, and approximately $90 \%$ at 14 days (Fig. 4 A, B, G and H). As evidenced by qPCR (Fig. 4I and J), mRNA expression of the GSK-3beta/ beta-catenin pathway target genes, including axin 2 and cyclin D1, was markedly reduced in shCx43 BMSCs compared to those in CON and NC cells after 7 or 14 days of osteogenic induction. Taken together, these results thus support the view that $\mathrm{Cx} 43$ acts as a positive regulator of the GSK-3beta/beta-catenin pathway.

LiCl partially rescues the inhibitory effects of Cx43 on BMSC osteogenic differentiation by the GSK-3beta/beta-catenin signaling pathway

To further confirm the role of the GSK-3beta/beta-catenin pathway in osteogenesis observed in shCx43 BMSCs, cells underwent osteogenic differentiation with OIM or were treated with OIM in the presence of $5 \mathrm{mM} \mathrm{LiCl}$, an inhibitor of GSK-3beta. ALP was quantified by an enzymatic assay. After differentiation for 9 days, ALP activity was almost $40 \%$ higher in LiCl-treated shCx43 BMSCs compared with untreated cells (Fig. 5A). We then 


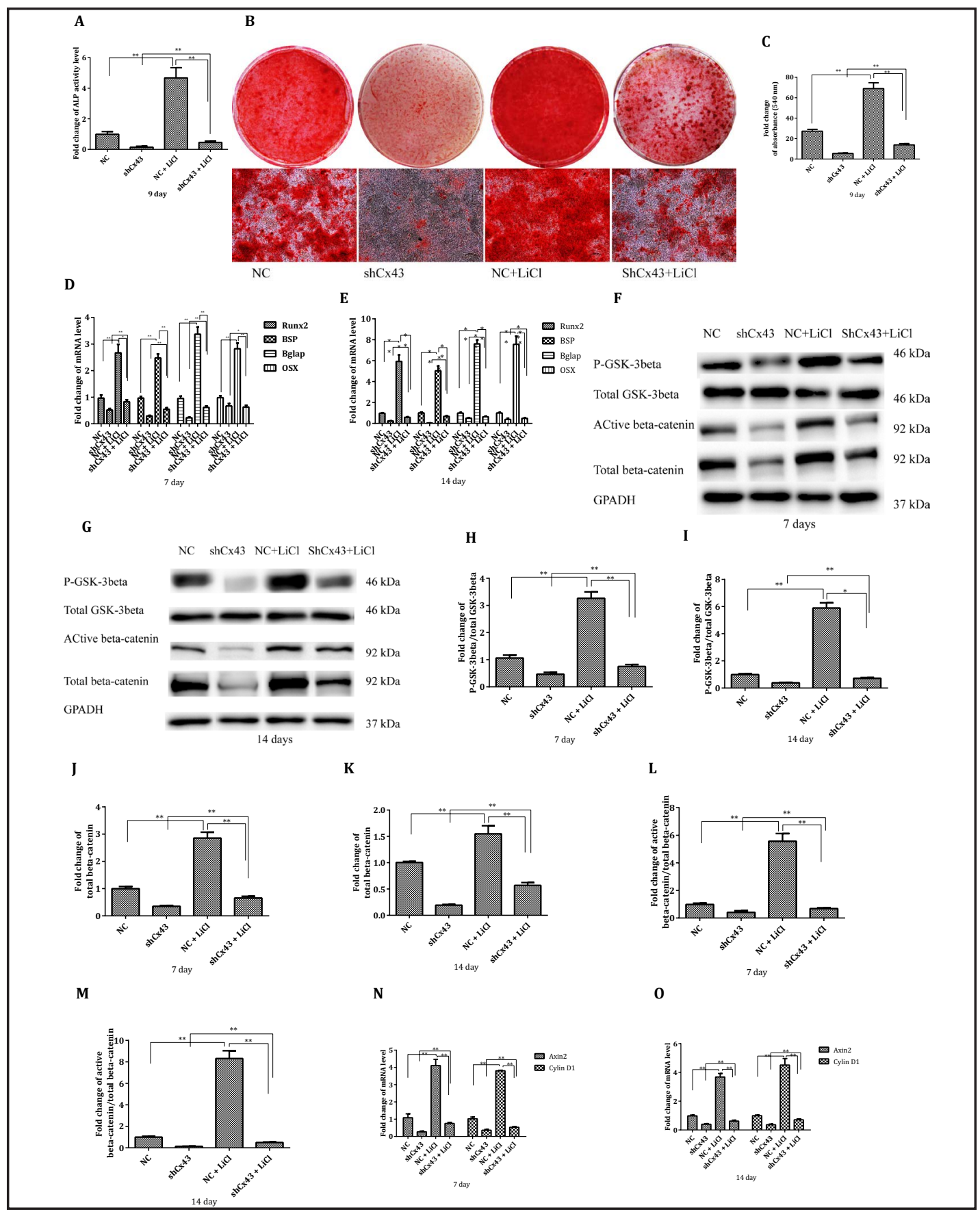

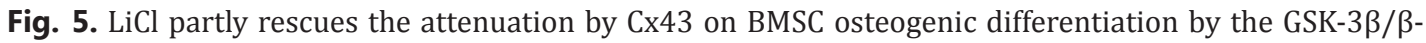
catenin signaling pathway. ShCx43 BMSCs were cultured in with OIM or were treated with OIM in presence of $5 \mathrm{mM} \mathrm{LiCl}$. (A), ALP activity of BMSCs was measured at 9 days after differentiation. (B), Osteogenesis was assessed by alizarin red S staining after 14 days of differentiation. Bar indicates $100 \mu \mathrm{m}$. (C), Quantification of alizarin red S staining. (D and E), Expression of Runx2, BSP, Bglap and OSX was measured by real-time RT-

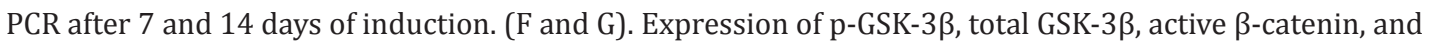
total $\beta$-catenin was analyzed by western blotting after 7 and 14 days of induction. Phospho-GSK-3beta/total GSK-3beta (F and G), total beta-catenin ( $\mathrm{H}$ and I) and active beta-catenin/total beta-catenin ( $\mathrm{J}$ and $\mathrm{K}$ ) were quantified. (N and O). Axin 2 and cyclin D1 mRNA levels were measured by real-time RT-PCR after 7 and 14 days of induction. Data are expressed as the mean \pm SD of the fold change of the values in shCx43 BMSCs. Values represent analysis from three separate experiments $\left({ }^{*} \mathrm{p}<0.05,{ }^{* *} \mathrm{p}<0.01\right)$.

\section{KARGER}


performed alizarin red S staining to measure mineralization at 14 days following osteogenic differentiation. Compared to untreated cells, there was a nearly 7 -fold increase in the total extent of mineralization following LiCl treatment (Fig. 5B and C). Following differentiation for 7 days in the presence or absence of $\mathrm{LiCl}$, LiCl treatment elevated the mRNA levels of Runx2, BSP, Bglap, and OSX (Fig. 5D), and similar results were obtained after 14 days of differentiation (Fig. 5E). Moreover, western blot analysis showed that the level of p-GSK3 beta was markedly increased in response to LiCl treatment, being $40 \%$ elevated after 7 days of differentiation (Fig. 5F and H), and about 3-fold elevated after 14 days of differentiation, compared to cells without LiCl treatment (Fig. 5G and I). Consistent with this, LiCl treatment increased the level of total beta-catenin when examined either at 7 days or 14 days following induction of differentiation (Fig. 5F, G, J and K). Similarly, a dramatic increase of active beta-catenin was also observed, both after 7 days (Fig. 5L) and 14 days (Fig. 5M) following osteogenic differentiation with OIM containing $\mathrm{LiCl}$. In addition, $\mathrm{LiCl}$ treatment resulted in a pronounced increase in the mRNA levels for axin 2 and cyclin D1 after 7 and 14 days of differentiation (Fig. $5 \mathrm{~N}$ and 0 ). Thus, our findings indicate that $\mathrm{LiCl}$ partially rescues the inhibitory effects of Cx43 knockdown on BMSC osteogenic differentiation by enhancing the GSK-3beta/beta-catenin signaling pathway.

\section{Discussion}

In the present study, we demonstrate that $\mathrm{Cx} 43$ expression markedly increases during osteogenic differentiation of BMSCs, and knockdown of $\mathrm{Cx} 43$ results in decreased mRNA levels for osteogenesis marker genes, cellular ALP enzymatic activity and levels of calcium nodules. Furthermore, we show that attenuated osteogenesis involves decreased levels and activity of beta-catenin due to increased GSK-3beta activity. These findings demonstrate that connexin 43 modulates osteogenic differentiation of bone marrow stromal cells through the GSK-3beta/beta-catenin signaling pathway.

Knock down of $\mathrm{Cx} 43$ in mice results in perinatal death as a result of impaired cardiac function [41, 42], and causes low bone mass and osteoblast dysfunction [43]. Oculodentodigital dysplasia is a developmental disorder associated with mutations in the Cx43 gene Gja1, leading to a skeletal phenotype characterized by syndactyly of the hands and feet, hypoplasia or aplasia of the phalanges and craniofacial abnormalities [44]. Many Cx43-deficient animal models, generated by means of gene mutation or conditional gene knockout, exhibit different extents of destructive cortical bone modeling and trabecular bone remodeling, or deteriorated bone quality. It has been established by in vitro studies that $\mathrm{Cx} 43$ expression is required for normal osteoblastic gene expression and function. For instance, overexpression of Cx43 in MC3T3-E1 osteoblasts increases the transcriptional activity of a Runx2 reporter in response to fibroblast growth factor-2 (FGF-2) treatment [28], whereas siRNA-mediated knockdown of $\mathrm{Cx} 43$ suppresses Runx2-dependent transcription, including Col1a1, Bglap, and Osx [45]. Similar consequences are shown by human fetuses upon loss of $\mathrm{Cx} 43$, resulting in decreased alkaline phosphatase (ALP) activity, and Bglap, osteopontin and Cbfa1 expression [46]. Stable transfection with Cx43 significantly promotes proliferation and differentiation, and mineralization, as well as expression of ALP [21], osteocalcin and bone sialoprotein [28] in UMR 106 osteoblasts. Furthermore, Cx43-deficient osteoblasts from $\mathrm{Cx} 43$-null mice causes impaired differentiation and delayed mineralization compared to osteoblasts from wild-type mice [29]. These findings imply a role for Cx43 in the cellular differentiation and mineralization processes of osteoblasts. Several types of agents, such as transforming growth factor (TGF)-beta and BMP2, contribute to maintain a dynamic balance between osteogenesis and adipogenesis in the bone marrow [47]. In the present study, we find that $\mathrm{Cx} 43$ expression increases during BMSC differentiation, and lentivirus-mediated knockdown of $\mathrm{Cx} 43$ expression diminishes osteogenesis of BMSCs, as judged by decreased ALP activity, mineralization and expression of osteogenesis marker genes. Therefore, our results further indicate that $\mathrm{Cx} 43$ could be a regulatory factor of osteogenesis in BMSC 
differentiation.

Here, we examine the effects of $\mathrm{Cx} 43$ on osteogenic differentiation of BMSCs by characterizing ALP enzymatic activity and the expression levels of the Runx2, BSP, Bglap, and OSX genes. ALP is a bone-specific enzyme and is considered a vital marker for osteogenic differentiation, the presence of which is essential for bone formation [48, 49]. Runx2, an important transcription factor necessary for osteoblast differentiation and bone formation, controls expression of the Bglap and osteopontin genes [50,51]. Numerous in vitro and in vivo studies have shown that early osteogenic differentiation at the level of Runx2 is among the primary mechanisms by which $\mathrm{Cx} 43$ exerts its action on bone cells [52-57]. Our results are consistent with a previous report showing inhibition of $\mathrm{Cx} 43$ decreases the expression of Runx2 during differentiation of hBMSC into osteoblasts [53]. Osterix is a novel zinc fingercontaining transcription factor that is essential for osteoblast differentiation and bone formation [58]. BSP is an acidic, non-collagenous glycoprotein abundantly expressed in mineralized tissues, and is frequently used as a marker of osteoblast differentiation [59]. The absence of any osteogenic differentiation marker gene leads to a lack of cell differentiation and mineralization of bone tissue [49-51, 58,59]. Overexpression of connexin $43(\mathrm{Cx} 43)$ has been shown to enhance both the magnitude and spatial distribution of GJIC and osteogenic differentiation markers in 3D culture [30]. Consistent with this, knockdown of $\mathrm{Cx} 43$ attenuates expression of osteogenesis marker genes in both early and later periods of BMSC osteogenesis. These results clearly indicate that $\mathrm{Cx} 43$ promotes BMSC osteogenic differentiation by up-regulation of osteogenic marker gene expression.

Activation of Wnt/beta-catenin signaling suppresses adipogenesis and promotes osteogenesis of BMSCs [33, 34]. GSK-3beta is a key component of the Wnt/beta-catenin signaling pathway and can directly control beta-catenin activity. Beta-catenin suffers proteasomal degradation due to phosphorylation at Ser33, Ser37, and Thr41 by GSK-3beta, and consequently the transcription of beta-catenin responsive osteogenic genes is suppressed [60]. Beta-catenin is stable and active when dephosphorylated at Ser33, Ser37, and Thr41. The activity of GSK-3beta can be inhibited by phosphorylation at Ser-9 [61]. Furthermore, the impact of Cx43 on beta-catenin activity and GSK are also well established [56, 57, 62], whereas the mechanism by which the defects in $\mathrm{Cx} 43$ cause skeletal development deficiency has not been shown [17]. Our research involves the roles of Cx43 in skeletal development. We show that inhibition of $\mathrm{Cx} 43$ enhances GSK-3beta activity, and diminishes not only the level of total beta-catenin, but also the level of active beta-catenin and expression of Wnt target genes axin 2 and cyclin D1. Interestingly, treatment with $\mathrm{LiCl}$, an inhibitor of GSK3 beta [60], partially rescues the inhibition of osteogenic differentiation resulting from Cx43 depletion, and reduces GSK-3beta and total beta-catenin levels, as well as activates betacatenin and Wnt target genes. Although the link between $\mathrm{Cx} 43$ and GSK-3beta needs to be further clarified in future investigation, these results indicate there is a Cx43/GSK-3beta/ beta-catenin signaling axis that regulates osteogenic differentiation of BMSCs.

However, it is noteworthy the effects of $\mathrm{Cx} 43$ deficiency in different contexts involves diverse interactions of $\mathrm{Cx} 43$ with the Wnt/beta-catenin pathway [63]. In contrast, Cx43deficient ulnae and Cx43-silenced MLO-Y4 osteocyte-like cells elevate basal beta-catenin protein levels to respond to mechanical forces, and is accompanied by increases in the levels of the beta-catenin/Wnt target genes axin 2 and Sfrp4 [64]. In addition, similar correlativity is exhibited in cardiac myocytes [65], neural progenitor cells [66], seminiferous epithelium [67] and mammary epithelial cells [68]. Lloyd and colleagues have shown that $\mathrm{Cx} 43$ deficiency leads to enhanced beta-catenin, and have suggested that $\mathrm{Cx} 43$ serves as a target of Wnt/beta-catenin to regulate a negative feedback loop responsible for bone cell responses to anabolic stimuli [69]. Thus, $\mathrm{Cx} 43$ is increased in the context of loading, which in turn sequesters beta-catenin, leading to a decrease in beta-catenin-mediated stimulation of Cx43 expression, thus closing the negative feedback loop [64]. Furthermore, consistent with our study, downregulation of $\mathrm{Cx} 43$ in failing hearts from spontaneously hypertensive rats is related to reduced inactivating phosphorylation of GSK-3beta [70]. On the other hand, Cx43 deficiency results in alterations in the mineralization and remodeling phases of fracture 
healing, and is characterized by delayed expression of osteogenic marker genes, increases in GSK-3beta mRNA and active GSK-3beta, consistent with a pronounced decrease in betacatenin expression. At the same time, alterations in healing of fractures, in $\mathrm{Cx} 43$ deficiency, can be rescued by inhibiting GSK-3beta activity using LiCl [32]. BMSCs play an important role in fracture repair, and BMSC commitment to the chondrogenic or osteogenic lineages improves healing, after homing to the site of fracture, by increasing bone formation $[71,72]$. An increase or activation of beta-catenin could promote osteogenesis of BMSCs and bone formation [73]. Thus, our data combined with previous reports suggests that upregulation of $\mathrm{Cx} 43$ could promote fracture repair by raising and activating GSK-3beta/beta-catenin signaling, which is associated with enhancement of osteogenesis of BMSCs.

In summary, we demonstrate that $\mathrm{Cx} 43$ plays an essential role in regulating osteogenic differentiation of BMSCs. Moreover, we substantiate the GSK-3beta/beta-catenin pathway to be involved in downstream signaling of $\mathrm{Cx} 43$ to enhance osteogenic differentiation of BMSCs, and serves as part of the mechanism by which $\mathrm{Cx} 43$ regulates osteogenic differentiation of BMSCs. This sheds new light that $\mathrm{Cx} 43$ has a potential therapeutic role as an osteogenesis modulator through modulating bone mass and bone mineral density during osteogenic differentiation of BMSCs.

\section{Acknowledgements}

The study is supported by the National Natural Science Foundation of China (No. 81341103, 61271947), the Natural Science Foundation of Guangdong Province, China (No. 2014A030313467), the Medical Scientific Research Foundation of Guangdong Province, China (No. A2018523).

\section{Disclosure Statement}

The authors declare that they have conflict of interests.

\section{References}

1 Phinney DG, Kopen G, Isaacson RL, Prockop DJ: Plastic adherent stromal cells from the bone marrow of commonly used strains of inbred mice: variations in yield, growth, and differentiation. J Cell Biochem 1999;72:570-585.

-2 Jiang Y, Jahagirdar BN, Reinhardt RL, Schwartz RE, Keene CD, Ortiz-Gonzalez XR, Reyes M, Lenvik T, Lund T, Blackstad M, Du J, Aldrich S, Lisberg A, Low WC, Largaespada DA, Verfaillie CM: Pluripotency of mesenchymal stem cells derived from adult marrow. Nature 2002;418:41-49.

-3 Beresford JN, Bennett JH, Devlin C, Leboy PS, Owen ME: Evidence for an inverse relationship between the differentiation of adipocytic and osteogenic cells in rat marrow stromal cell cultures. J Cell Sci 1992;102:341-351.

4 Post S, Abdallah BM, Bentzon JF, Kassem M: Demonstration of the presence of independent pre-osteoblastic and pre-adipocytic cell populations in bone marrow-derived mesenchymal stem cells. Bone 2008;43:32-39.

5 Muruganandan S, Roman AA, Sinal CJ: Adipocyte differentiation of bone marrow-derived mesenchymal stem cells: Cross talk with the osteoblastogenic program. Cell Mol Life Sci 2009;66:236-253.

6 Di Iorgi N, Rosol M, Mittelman SD, Gilsanz V: Reciprocal relation between marrow adiposity and the amount of bone in the axial and appendicular skeleton of young adults. J Clin Endocr Metab 2008;93:2281-2286.

7 Qiu W, Andersen TE, Bollerslev J, Mandrup S, Abdallah BM, Kassem M: Patients with high bone mass phenotype exhibit enhanced osteoblast differentiation and inhibition of adipogenesis of human mesenchymal stem cells. J Bone Miner Res 2007;22:1720-1731.

-8 Meunier P, Aaron J, Edouard C, Vignon G: Osteoporosis and the replacement of cell populations of the marrow by adipose tissue. A quantitative study of 84 iliac bone biopsies. Clin Orthop Relat R 1971;80:147154.

-9 Rosen CJ, Bouxsein ML: Mechanisms of disease: is osteoporosis the obesity of bone? Nat Clin Pract Rhe 2006;2:35-43. 


\section{Cellular Physiology Cell Physiol Biochem 2018;47:161-175 \begin{tabular}{lll} 
DOI: 10.1159/000489763 & Ond Biochemistry \\
Published online: May 16, 2018 & $\begin{array}{l}\text { 2018 The Author(s). Published by S. Karger AG, Basel } \\
\text { www.karger.com/cpb }\end{array}$ \\
\cline { 1 - 3 }
\end{tabular}}

Lin et al.: Cx43 Modulates Osteogenic Differentiation

10 Savopoulos C, Dokos C, Kaiafa G, Hatzitolios A: Adipogenesis and osteoblastogenesis: trans-differentiation in the pathophysiology of bone disorders. Hippokratia 2011;15:18-21.

11 Han W, Yu Y, Liu XY: Local signals in stem cell-based bone marrow regeneration. Cell Res 2006;16:189-195.

$\checkmark 12$ Hoemann CD, El-Gabalawy H, McKee MD: In vitro osteogenesis assays: Influence of the primary cell source on alkaline phosphatase activity and mineralization. Pathol Biol 2009;57:318-323.

13 Abdallah BM, Jafari A, Zaher W, Qiu W, Kassem M: Skeletal (stromal) stem cells: An update on intracellular signaling pathways controlling osteoblast differentiation. Bone 2015;70:28-36.

14 Donahue HJ: Gap junctions and biophysical regulation of bone cell differentiation. Bone 2000;26:417-422.

-15 Unger VM, Kumar NM, Gilula NB, Yeager M: Three-dimensional structure of a recombinant gap junction membrane channel. Science 1999;283:1176-1180.

16 Batra N, Kar R, Jiang JX: Gap junctions and hemichannels in signal transmission, function and development of bone. BBA-Biomembranes 2012;1818:1909-1918.

17 Merrifield PA, Laird DW: Connexins in skeletal muscle development and disease. Semin Cell Dev Biol 2016;50:67-73.

18 Plotkin LI, Laird DW, Amedee J: Role of connexins and pannexins during ontogeny, regeneration, and pathologies of bone. Bmc Cell Biol 2016;17: 29-38

19 Plotkin LI, Manolagas SC, Bellido T: Transduction of cell survival signals by connexin-43 hemichannels. J Biol Chem 2002;277:8648-8657.

20 Gramsch B, Gabriel HD, Wiemann M, Grummer R, Winterhager E, Bingmann D, Schirrmacher K: Enhancement of connexin 43 expression increases proliferation and differentiation of an osteoblast-like cell line. Exp Cell Res 2001;264:397-407.

21 Lima F, Niger C, Hebert C, Stains JP: Connexin43 Potentiates Osteoblast Responsiveness to Fibroblast Growth Factor 2 via a Protein Kinase C-Delta/Runx2-dependent Mechanism. Mol Biol Cell 2009;20:26972708.

-22 Plotkin LI: Connexin 43 hemichannels and intracellular signaling in bone cells. Front Physiol 2014;5:131. Plotkin LI, Bellido T: Beyond gap junctions: Connexin43 and bone cell signaling. Bone 2013;52:157-166.

-24 Buo AM, Stains JP: Gap junctional regulation of signal transduction in bone cells. Febs Lett 2014;588:13151321.

25 Stains JP, Civitelli R: Connexins in The Skeleton. Semin Cell Dev Biol 2016;50:31-39.

26 Moorer MC, Stains JP: Connexin43 and the Intercellular Signaling Network Regulating Skeletal Remodeling. Curr Osteoporos Rep 2017;15:24-31.

27 Grimston SK, Fontana F, Watkins M, Civitelli R: Heterozygous deletion of both sclerostin (Sost) and connexin43 (Gja1) genes in mice is not sufficient to impair cortical bone modeling. Plos One 2017;12:e0187980.

28 Lecanda F, Towler DA, Ziambaras K, Cheng SL, Koval M, Steinberg TH, Civitelli R: Gap junctional communication modulates gene expression in osteoblastic cells. Mol Biol Cell 1998;9:2249-2258.

29 Lecanda F, Warlow PM, Sheikh S, Furlan F, Steinberg TH, Civitelli R: Connexin43 deficiency causes delayed ossification, craniofacial abnormalities, and osteoblast dysfunction. J Cell Biol 2000;151:931-944.

-30 Rosselló RA, Wang Z, Kizana E, Krebsbach PH, Kohn DH, Langer R: Connexin 43 as a Signaling Platform for Increasing the Volume and Spatial Distribution of Regenerated Tissue. P Natl Acad Sci U S A 2009;106:13219-13224.

-31 Loiselle AE, Paul EM, Lewis GS, Donahue HJ: Osteoblast and osteocyte-specific loss of Connexin43 results in delayed bone formation and healing during murine fracture healing. J Orthop Res 2013;31:147-154.

-32 Loiselle AE, Lloyd SAJ, Paul EM, Lewis GS, Donahue HJ: Inhibition of GSK-3 $\beta$ Rescues the Impairments in Bone Formation and Mechanical Properties Associated with Fracture Healing in Osteoblast Selective Connexin 43 Deficient Mice. Plos One 2013;8:e81399.

-33 Krishnan V, Bryant HU, Macdougald OA: Regulation of bone mass by Wht signaling. J Clin Invest 2006;116:1202-1209.

-34 Cawthorn W, Bree AJ, Yao Y, Du B, Hemati N, Martinezsantibanez G, Macdougald OA: Wnt6, Wnt10a and Wnt10 b inhibit adipogenesis and stimulate osteoblastogenesis through a beta-catenin-dependent mechanism. Bone 2012;50:477-489

-35 Kim JH, Liu X, Wang J, Chen X, Zhang H, Kim SH, Cui J, Li R, Zhang W, Kong Y: Wnt signaling in bone formation and its therapeutic potential for bone diseases. Ther Adv Muscul Dis 2013;5:13-31. 


\section{Cellular Physiology Cell Physiol Biochem 2018;47:161-175

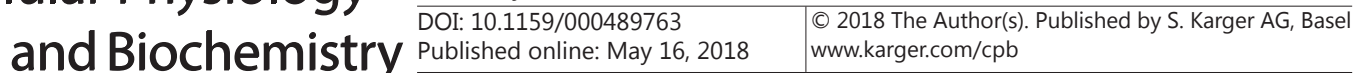

Lin et al.: Cx43 Modulates Osteogenic Differentiation

-36 Liu C, Li Y, Semenov M, Han C, Baeg GH, Tan Y, Zhang Z, Lin X, He X: Control of beta-catenin phosphorylation/degradation by a dual-kinase mechanism. Cell 2002;108:837-847.

-37 Ling L, Nurcombe V, Cool SM: Wnt signaling controls the fate of mesenchymal stem cells. Gene 2009;433:17.

-38 Friedenstein AJ, Latzinik NV, Yuf G, Luria EA, Moskvina IL: Bone marrow stromal colony formation requires stimulation by haemopoietic cells. Bone Miner 1992;18:199-213.

39 Meirelles LS, Nardi NB: Murine marrow-derived mesenchymal stem cell: isolation, in vitro expansion, and characterization. Brit J Haematol 2003;123:702-711.

-40 Elias LA, Wang DD, Kriegstein AR: Gap junction adhesion is necessary for radial migration in the neocortex. Nature 2007;448:901-907.

-41 Ya J, Erdtsieckernste EB, de Boer PA, van Kempen MJ, Jongsma H, Gros D, Moorman AF, Lamers WH: Heart defects in connexin43-deficient mice. Circ Res 1998;82:360-366.

42 Reaume AG, de Sousa PA, Kulkarni S, Langille BL, Zhu D, Davies TC, Juneja SC, Kidder GM, Rossant J: Cardiac malformation in neonatal mice lacking connexin43 Science 1995;267:1831-1834.

43 Thi MM, Urban-Maldonado M, Spray DC, Suadicani SO: Characterization of hTERT-immortalized osteoblast cell lines generated from wild-type and connexin43-null mouse calvaria. Am J Physiol-Cell Ph 2010;299:C994-C1006.

44 Richardson R, Donnai D, Meire F, Dixon M: Expression of Gja1 correlates with the phenotype observed in oculodentodigital syndrome/type III syndactyly. J Med Genet 2004;41:60-67.

45 Niger C, Buo AM, Hebert C, Duggan BT, Williams MS, Stains JP: ERK acts in parallel to PKC $\delta$ to mediate the connexin43-dependent potentiation of Runx2 activity by FGF2 in MC3T3 osteoblasts. Am J Physiol Cell-Ph 2012;302:C1035-C1044

46 Li ZY, Zhou ZY, Saunders MM, Donahue HJ: Modulation of connexin43 alters expression of osteoblastic differentiation markers. Am J Physiol Cell-Ph 2006;290:1248-1255.

47 Hoshiba T, Kawazoe N, Chen G: The balance of osteogenic and adipogenic differentiation in human mesenchymal stem cells by matrices that mimic stepwise tissue development. Biomaterials 2012;33:20252031.

48 Whyte MP: Hypophosphatasia and the role of alkaline phosphatase in skeletal mineralization. Endocr Rev 1994;15:439-461.

49 Hessle L, Johnson KA, Anderson HC, Narisawa S, Sali A, Goding JW, Terkeltaub R, Millán JL: TissueNonspecific Alkaline Phosphatase and Plasma Cell Membrane Glycoprotein-1 are Central Antagonistic Regulators of Bone Mineralization. Proc Natl Acad Sci U S A 2002;99:9445.

50 Franceschi RT, Xiao G: Regulation of the osteoblast-specific transcription factor, Runx2: responsiveness to multiple signal transduction pathways. J Cell Biochem 2003;88:446-454.

51 Zhao Z, Zhao M, Xiao G, Franceschi RT: Gene Transfer of the Runx2 Transcription Factor Enhances Osteogenic Activity of Bone Marrow Stromal Cells in vitro and in vivo. Mol Ther 2005;12:247-253.

-52 Carla Hebert JPS: An Intact Connexin43 is Required to Enhance Signaling and Gene Expression in Osteoblast-like Cells. J Cell Biochem 2013;114:2542-2550.

53 Yang H, Shi L, Shi G, Guo Y, Chen D, Chen D, Shi J: Connexin 43 Affects Osteogenic Differentiation of the Posterior Longitudinal Ligament Cells via Regulation of ERK Activity by Stabilizing Runx2 in Ossification. Cell Physiol Biochem 2016;38:237-247.

54 Lima F, Niger C, Hebert C, Stains JP: Connexin43 Potentiates Osteoblast Responsiveness to Fibroblast Growth Factor 2 via a Protein Kinase C-Delta/Runx2-dependent Mechanism. Mol Biol Cell 2009;20:26972708.

55 Talbot J, Brion R, Lamora A, Mullard M, Morice S, Heymann D, Verrecchia F: Connexin43 Intercellular Communication Drives the Early Differentiation of Human Bone Marrow Stromal Cells into Osteoblasts. J Cell Physiol 2018;233:946-957.

56 Buo AM, Tomlinson RE, Eidelman ER, Chason M, Stains JP: Connexin43 and Runx2 Interact to Affect Cortical Bone Geometry, Skeletal Development, and Osteoblast and Osteoclast Function. J Bone Miner Res 2017;32:1727-173856 6057

57 Moorer MC, Hebert C, Tomlinson RE, Iyer SR, Chason M, Stains JP: Defective signaling, osteoblastogenesis and bone remodeling in a mouse model of connexin 43 C-terminal truncation. J Cell Sci 2017;130:531-540. 


\section{Cellular Physiology Cell Physiol Biochem 2018;47:161-175 \begin{tabular}{l|l} 
DOI: 10.1159/000489763 & Ond Biochemistry 2018 The Author(s). Published by S. Karger AG, Basel \\
Published online: May 16, 2018 & \begin{tabular}{l} 
www.karger.com/cpb \\
\hline
\end{tabular}
\end{tabular}}

Lin et al.: Cx43 Modulates Osteogenic Differentiation

58 Nakashima K, Zhou X, Kunkel G, Zhang Z, Deng JM, Behringer RR, De CB: The novel zinc finger-containing transcription factor osterix is required for osteoblast differentiation and bone formation. Cell 2002;108: 17-29.

59 Gordon JA, Tye CE, Sampaio AV, Underhill TM, Hunter GK, Goldberg HA: Bone sialoprotein expression enhances osteoblast differentiation and matrix mineralization in vitro. Bone 2007;41:462-473.

60 Yost C, Torres M, Miller JR, Huang E, Kimelman D, Moon RT: The axis-inducing activity, stability, and subcellular distribution of beta-catenin is regulated in Xenopus embryos by glycogen synthase kinase 3 Genes Dev 1996;10:1443-1454.

61 Grimes CA, Jope RS: The multifaceted roles of glycogen synthase kinase 3beta in cellular signaling. Prog Neurobiol 2001;65:391-426.

62 Watkins M, Grimston SK, Norris JY, Guillotin B, Shaw A, Beniash E, Civitelli R: Osteoblast connexin43 modulates skeletal architecture by regulating both arms of bone remodeling. Mol Biol Cell 2011;22:12401251.

63 Lloyd SA, Loiselle AE, Zhang Y, Donahue HJ: Shifting Paradigms on the Role of Connexin43 in the Skeletal Response to Mechanical Load. J Bone Miner Res 2014;29:275-286.

64 Bivi N, Pacheco-Costa R, Brun LR, Murphy TR, Farlow NR, Robling AG, Bellido T, Plotkin LI: Absence of Cx43 selectively from osteocytes enhances responsiveness to mechanical force in mice. J Orthop Res 2013;31:1075-1081.

65 Arjm F, Adriaens A: Wnt-1 regulation of connexin43 in cardiac myocytes. Journal Clin Invest 2000;105:161171.

66 Rinaldi F, Hartfield EM, Crompton LA, Badger JL, Glover CP, Kelly CM, Rosser AE, Uney JB, Caldwell MA: Cross-regulation of Connexin43 and $\beta$-catenin influences differentiation of human neural progenitor cells. Cell Death Dis 2014;5:e1017.

67 Dbouk HA, Mroue RM, Elsabban ME, Talhouk RS: Connexins: a myriad of functions extending beyond assembly of gap junction channels. Cell Commun Signal 2009;7:1-17.

68 Talhouk RS, Mroue R, Mokalled M, Abi-Mosleh L, Nehme R, Ismail A, Khalil A, Zaatari M, El-Sabban ME: Heterocellular interaction enhances recruitment of alpha and beta-catenins and ZO-2 into functional gapjunction complexes and induces gap junction-dependant differentiation of mammary epithelial cells. Exp Cell Res 2008;314:3275-3291.

69 Heyden MAVD, Rook MB, Hermans MM, Rijksen G, Boonstra J, Defize LH, Destree OH: Identification of connexin43 as a functional target for Wnt signalling. J Cell Sci 1998;111:1741-1749.

70 Karl S, Ziegelhöffer B, Raßler B, Salameh A: Connexin 43 expression is impaired in beginning heart failure in spontaneously hypertensive rats. Cell Commun Signal 2009;7:1-1.

71 Šponer P, Kučera T, Diaz-Garcia D, Filip S: The role of mesenchymal stem cells in bone repair and regeneration. Eur J Orthop Surg Tr 2013;24:257-262.

72 Bielby R, Jones E, Mcgonagle D: The role of mesenchymal stem cells in maintenance and repair of bone. Injury 2007;38:S26-S32.

73 Gaur T, Lengner CJ, Hovhannisyan H, Bhat RA, Bodine PV, Komm BS, Javed A, van Wijnen AJ, Stein JL, Stein GS: Canonical WNT signaling promotes osteogenesis by directly stimulating Runx2 gene expression. J Biol Chem 2005;280:33132-33140. 